\title{
Complexities and challenges of surgical data collection from cataract patients: comparison of cataract surgery rates between 2001 and 2008 in all provinces of Argentina
}

\author{
Complexidades e desafios da coleta de dados cirúrgicos de catarata: comparação das taxas de \\ cirurgia de catarata em todas as províncias da Argentina de 2001 em relação a 2008
}

Van C. Lansingh ${ }^{1}$, Maria E. Nano ${ }^{2}$, Marissa J. Carter $^{3}$, Natalia Zárate ${ }^{2}$, Serge Resnikoff ${ }^{4}$, Kristen A. Eckert $^{3}$

\begin{abstract}
Purpose: To compare the cataract surgical rate (CSR) in 2001 with that in 2008 in all Argentinean provinces using current reporting methods and verify the accuracy of CSRs by cross-checking these methods with the number of sold intraocular lenses (IOLs) within the country.

Methods: Alongitudinal study including public and private set-ups was conducted, and it included 40 ophthalmologists from 22 provinces who provided cataract surgery data for 2001 and 2008. Other data were obtained from the Ministry of Health. Estimates were cross-checked against the market data for sold intraocular lens (IOLs) in 2008 and 2010

Results: The number of cataract surgeries increased 2.7-fold, from 62,739 in 2001 to 169,762 in 2008 , with increases in every province except Mendoza. Although the population also increased by $9.4 \%$ during the same time period, the apparent CSR jumped from 1,744 to 4,313 per million population. The number of IOLs sold in Argentina in 2008 was 186,652, suggesting that the number of cataract surgeries performed was slightly greater than anticipated. Cross-checks with other countries using IOL sales data did not show discrepancies when compared with previously reported CSRs.

Conclusions: Although the CSR in Argentina increased considerably from 2001 to 2008 for several reasons, the main reason was that thorough cross-checking between the number of surgeries reported and the number of IOLs sold revealed that the number of surgeries performed annually were being underestimated as a result of incomplete reporting by private practitioners. Furthermore, the presence of multiple societies of ophthalmology in the country complicated the process of obtaining accurate data.
\end{abstract}

Keywords: Cataract/epidemiology; Argentina; Health services research/statistics \& numerical data

\section{RESUMO}

Objetivo: Comparar a taxa de cirurgia de catarata (TCC) em todas as províncias da Argentina entre 2001 e 2008, utilizando métodos de relatórios convencionais everificar a precisão da TCC por meio do cruzamento desses métodos com o número de lentes intraoculares (LIOS) vendidas no país.

Métodos: Estudolongitudinal realizadoem clínicas públicas eprivadas, com a participação de 40 oftalmologistas de 22 províncias, que forneceram dados sobre cirurgias de catarata para 2001 e 2008. Outros dados foram obtidos a partir do Ministério da Saúde. As observações foram cruzadas com os dados de mercado para LIOs no período de 2008 a 2010. Resultados: O número de cirurgias de catarata aumentaram 2,7 vezes, de $62.739 \mathrm{em}$ 2001 para 169.762 em 2008, com aumentos em todas as províncias, exceto Mendoza. Embora a população também tenha aumentado 9,4\% durante o mesmo período de tempo, a aparente TCC saltou de 1.744 para 4.313 por milhão de população. O número de LIOsvendidas na Argentina em 2008foide 186.652, o que pode significar que tenham sido realizadas um pouco mais de cirurgias de catarata do que o estimado. Verificações cruzadas com outros países que utilizam dados de vendas de LIOs não apresentam discrepâncias quando comparado a TCC anteriormente relatadas.

Conclusões: De 2001 a 2008, a TCC na Argentina aumentou consideravelmente por várias razões mas, principalmente, porque foi revelada, por meio do cruzamento de dados sobre cirurgias relatadas com o número de LIOs vendidas, que o número de cirurgias realizadas anualmente foi hipoestimado no passado, como resultado de relatórios incompletos feitos por médicos privados. Há também várias sociedades de oftalmologia no país, o que dificulta a obtenção de dados precisos.

Descritores: Catarata/epidemiologia; Argentina; Pesquisa sobre serviços de saúdel estatística \& dados numéricos

\section{INTRODUCTION}

Cataract surgery is the most commonly performed surgery worldwide and one of the most cost-effective interventions ${ }^{(1,2)}$. Yet, in many developing countries, millions of individuals are still blind from cataract and have not undergone surgery. There are 2 indicators of cataract surgical services: cataract surgical rate (CSR) and cataract surgical coverage (CSC). CSR is the annual number of cataract surgeries performed per 1 million population. CSC is the annual proportion of cataract cases completed in a given population, thereby demonstrating the distribution and equity of services across different regions and populations.

To calculate cataract surgery needs, the number of individuals who are blind or visually impaired because of cataract (based on preoperative visual acuity) should first be estimated in each country. This estimate is projected as 5-10 years by modeling ${ }^{(3)}$. Furthermore, the size of a country and geographically disparate data with regard to

Submitted for publication: May 29, 2013

Accepted for publication: August 25,2013

Study was conducted at the International Agency for the Prevention of Blindness/VISION 2020 Latin America.

${ }^{1}$ International Agency for the Prevention of Blindness/VISION 2020 Latin America, Weston, FL 33331, USA.

Fundación Oftalmológica Hugo D. Nano, Buenos Aires, Argentina.

${ }^{3}$ Strategic Solutions, Inc., Cody, WY 82414, USA.

${ }^{4}$ International Health and Development, Geneva, Switzerland.

Financial support: This study was funded by ORBIS and the International Agency for the Prevention of Blindness.

Disclosure of potential conflicts of interest: V.C. Lansingh is employed by the IAPB; M.E. Nano is employed by Fundación Hugo Nano; M.J. Carter is employed by Strategic Solutions and is a paid consultant to ORBIS and the IAPB; N. Zárate is employed by Fundación Hugo Nano; S. Resnikoff, None; K.A. Eckert is a paid consultant to Strategic Solutions.

Correspondence address: Van C. Lansingh. International Agency for the Prevention of Blindness/VISION 2020 Latin America, 3720 San Simeon Cr. Weston, FL 33331, USA - Email: vlansingh@v2020la.org Institution responsible for the approval of the research ethics committee: Fundación Oftalmológica Hugo D. Nano.

Project number: 4013. 
visual impairment are also factors that must be considered. Next, the number of cataract surgeries performed on an annual basis and the country's capacity for surgeries have to be determined on the basis of the number of surgically active ophthalmologists in each district or province. Finally, postoperative visual acuities and sight restoration rates should be reported to assess whether outcomes are satisfactory. Epidemiological data are usually obtained from regional or national surveys using population sampling designs, such as the rapid assessment of cataract surgical services (RACSS) ${ }^{(4)}$ or the rapid assessment of avoidable blindness (RAAB) ${ }^{(5)}$ studies. The number of surgeries and outcomes is estimated from governmental or institutional records. Such data are often incomplete because of resource limitations or the lack of a mandate to collect surgical operation statistics. Consequently, the resulting situation can hamper the evaluation of whether needs and supplies are balanced and whether services are meeting future needs.

Most national surveys that cover entire countries are based on sampling strategies; consequently, they do not cover all surgeries ${ }^{(6-9)}$. In Argentina, although 2 RACSS studies have been conducted ${ }^{(10,11)}$, no data have been published on the number of cataract surgeries by province, except for brief details for 2001 (Nano ME, Nano H; available from: http://boletinocular.bvsalud.org/boletim.php?lang=es\&vision $l d=10192450200311$ \&unitld=10192449200351\&style=homepage).

To determine the reliability of the national reported CSRs, we assessed the reliability of current traditional sources using Argentina as an example of a well-developed country with many kinds of providers and major government activity. Therefore, the current study aimed to compare the CSR in 2001 with that in 2008 in all Argentinean provinces using a methodology used to report data to the World Health Organization (WHO) for the last several years. Then, the study verified this data by cross-checking the number of intraocular lenses (IOLs) sold within the country. The timing of this study was in line with the recent approval of the updated WHO Action Plan for the prevention of avoidable blindness and visual impairment 2014-19 (EB132/9), which now has mandated that CSRs be reported by governments.

\section{METHODS}

The study adhered to the tenets of the Declaration of Helsinki. The institutional review board of the Fundación Oftalmológica Hugo D. Nano determined that the study was exempt from formal review because it evaluated retrospective cataract surgical data and required no patient intervention.

The head and deputy head of each provincial society of ophthalmology were asked to recommend several high-volume surgeons who had performed the greatest number of surgeries and had best access to other provincial surgical and related data for participation in this study. The nominated ophthalmologists were contacted by phone or e-mail and invited to participate as local investigators. Participants were asked to obtain standardized data on cataract surgeries performed within each province, including population data, number of surgical centers, number of cataract surgeries performed in the public and private health sectors, number of ophthalmologists, and economic information. This information came from local provincial government sources such as the departments of health, industry representatives, and private clinics with high surgical volumes. Several follow-up calls were made in cases of non-response. Monthly information on the number of surgeries was requested for 12 months. Population information and economic data were verified and supplemented with National Census data from the Institute of Statistics and Census in Argentina. The number of ophthalmologists was estimated on the basis of data provided by various sources, including participating ophthalmologists, societies, and large commercial houses. Data on the number of IOLs sold in Argentina were obtained from suppliers to verify the number of cataract surgeries performed in 2008 through 2010. Although there is reason to believe that supplier data would be accurate (from all known suppliers with sales figures), this may not fully equate to the number of IOLs exactly used in a given year because of stockpiling, purchases by large institutions, and purchases by individuals that bypass customs.

Data collection issues meant that there were incomplete figures in Cordoba in 2008 and that data were not available for the private sector in Entre Ríos. For the private sector of Buenos Aires, the figure was calculated on the basis of the number of IOLs sold. Meanwhile, the Ministry of Health $(\mathrm{MOH})$ provided input on public sector numbers. Although this method has its limitations, it has worked for other provinces with complete data. This method has also been used in other countries, and similar data has been presented and analyzed from neighboring countries of Argentina in the Discussion to further validate this method.

\section{RESULTS}

In 2001 and 2008, data were collected from a total of 40 ophthalmologists (1-3 per province) in 22 provinces. Between 2001 and 2008, the population of Argentina increased by $9.6 \%$ to 39.4 million (Table 1), but the most important statistic was the nearly one-third increase in the population aged $\geq 50$ years (from 130,403 in 2001 to 172,154 in 2008), which is the age group at the greater risk of cataracts. During this same time period, the number of ophthalmologists was estimated to have increased from 3,417 to 4,079 (19.4\%). The number of ophthalmologists per million population increased from 95 to 104 (8.9\%).

While the number of cataract surgeries increased from 62,739 in 2001 to 169,762 in 2008 (2.7-fold increase), the change varied considerably by province (provincial geography: Figure 1). The majority of provinces experienced a $26 \%$ to $100 \%$ increase in surgeries (Figure 2). Only one province, Mendoza, experienced a decline in the total number of surgeries (Table 1); however, the proportion of public surgeries increased from 2001 to 2008 (Figure 3). In Cordoba, despite repeated attempts, we did not receive full cooperation from local ophthalmologists and local authorities; therefore, the data were incomplete. Most likely, there was no decline in the number of surgeries, but this could not be verified. Formosa, which reported no surgeries in 2001 despite having 15 ophthalmologists, reported 1,680 surgeries in 2008. The number of surgeries increased by more than 2-fold in 6 other provinces.

CSR increased in all but 2 provinces: Cordoba (as explained above) and Río Negro (Table 1). Río Negro exhibited a very small decline (approximately 3\%). The increases were impressive in Neuquen, La Rioja, Chaco, and Formosa. Overall, the national CSR increased from 1,744 to 4,313 per million.

The number of public surgeries-i.e., surgeries paid for by the government-increased from 5,762 to 14,614 (2.5-fold increase in absolute numbers); however, it decreased from $9.2 \%$ to $8.7 \%$ when considered as a percentage of the total number of surgeries. Fourteen provinces experienced an increase in the number of public surgeries while 8 experienced a decrease (Figure 3). In Entre Ríos, the local society of ophthalmology did not provide surgical data for either time period (Figure 3). The largest absolute increase occurred in Misiones (3.3-fold increase in absolute numbers), where the number of public surgeries in 2008 was relatively small (164). While the percentage of public surgeries also increased in the greater Buenos Aires metropolitan area (5.7\% to 8.3\%; 10.259 surgeries in 2008), there was a decrease in San Juan (30.4\% to 7.2\%), San Luis (16.7\% to 3.7\%), and Tucumán (16.3\% to $2.8 \%)$.

The number of IOLs sold in Argentina was 186,652 in 2008, of which 59,500 were paid for by the government under a private insurance scheme known as PAMI [Programa de Atención Médica Integral] and 127,152 were public/private sector surgeries. PAMI is considered a private provider that primarily offers health coverage to employees, who contribute a portion of their salary in each paycheck to the government fund, which then reimburses the PAMI insurance scheme. 
Table 1. Data on population, number of ophthalmologists and cataract surgeries, and cataract surgical rate in 2001 and 2008

\begin{tabular}{|c|c|c|c|c|c|c|c|c|c|c|}
\hline \multirow[b]{2}{*}{ Province } & \multicolumn{2}{|c|}{ Population 2001} & \multicolumn{2}{|c|}{ Population 2008} & \multicolumn{2}{|c|}{ Ophthalmologists } & \multicolumn{2}{|c|}{ Surgeries } & \multicolumn{2}{|c|}{ CSR $^{*}$} \\
\hline & Total & $\geq 50$ years & Total & $\geq 50$ years & 2001 & 2008 & 2001 & 2008 & 2001 & 2008 \\
\hline $\mathrm{BA}^{\dagger} \mathrm{CABA}^{\ddagger}$ & $16,587,449$ & $4,262,528$ & $17,952,101$ & $4,416,742$ & 2,023 & 2,242 & 35,000 & 123,288 & 2,110 & 6,868 \\
\hline Catamarca & 333,661 & 58,800 & 380,612 & 70,658 & 13 & 16 & 420 & 704 & 1,259 & 1,850 \\
\hline Chaco & 967,396 & 157,117 & $1,042,881$ & 183,328 & 48 & 56 & 600 & 2,706 & 620 & 2,595 \\
\hline Chubut & 413,240 & 74,224 & 455,607 & 91,116 & 22 & 46 & 400 & 1,343 & 968 & 2,948 \\
\hline Cordoba & $3,061,611$ & 744,025 & $3,340,041$ & 844,794 & 214 & 342 & 7,657 & $3,322^{\S}$ & 2,501 & $995^{5}$ \\
\hline Corrientes & 929,236 & 160,954 & $1,002,416$ & 183,487 & 55 & 84 & 600 & 1,110 & 646 & 1,107 \\
\hline Entre Ríos & $1,156,799$ & 256,988 & $1,242,547$ & 293,570 & 77 & 91 & 1,625 & 2,146 & 1,405 & 1,727 \\
\hline Formosa & 439,136 & 72,944 & 532,238 & 88,597 & 15 & 20 & 0 & 1,680 & 0 & 3,156 \\
\hline Jujuy & 611,484 & 98,485 & 670,766 & 118,883 & 28 & 31 & 580 & 956 & 949 & 1,425 \\
\hline La Rioja & 289,280 & 48,376 & 334,235 & 59,595 & 16 & 24 & 198 & 1,040 & 684 & 3,112 \\
\hline La Pampa & 298,460 & 70,184 & 329,576 & 82,190 & 13 & 19 & 500 & 1,558 & 1,675 & 4,727 \\
\hline Mendoza & $1,576,585$ & 352,146 & $1,711,416$ & 406,554 & 122 & 141 & 3,740 & 3,136 & 2,372 & 1,832 \\
\hline Misiones & 963,869 & 130,403 & $1,061,590$ & 172,154 & 30 & 33 & 250 & 304 & 259 & 286 \\
\hline Neuquen & 473,315 & 73,542 & 538,952 & 98,054 & 28 & 67 & 860 & 3,342 & 1,817 & 6,201 \\
\hline Río Negro & 552,677 & 105,259 & 594,189 & 128,206 & 41 & 47 & 750 & 785 & 1,357 & 1,321 \\
\hline Salta & $1,079,420$ & 171,078 & $1,202,753$ & 203,523 & 56 & 64 & 1,220 & 1,521 & 1,130 & 1,265 \\
\hline San Juan & 622,094 & 125,088 & 685,883 & 146,326 & 48 & 52 & 1,150 & 1,551 & 1,849 & 2,261 \\
\hline San Luis & 366,900 & 72,468 & 428,025 & 88,304 & 37 & 46 & 600 & 1,558 & 1,635 & 3,640 \\
\hline Santa Cruz & 197,000 & 30,770 & 221,871 & 38,934 & 23 & 31 & 219 & 463 & 1,112 & 2,087 \\
\hline Santa Fe & $2,997,376$ & 753,313 & $3,242,551$ & 835,283 & 354 & 458 & 3,760 & 4,555 & 1,254 & 1,405 \\
\hline Santiago del Estero & 806,347 & 145,009 & 856,739 & 156,774 & 44 & 53 & 840 & 1,881 & 1,042 & 2,196 \\
\hline Tierra del Fuego & 100,960 & 11,466 & 126,212 & 17,759 & 10 & 11 & 170 & 223 & 1,684 & 1,767 \\
\hline Tucumán & $1,142,105$ & 246,927 & $1,457,357$ & 293,785 & 100 & 123 & 1,600 & 6,790 & 1,401 & 4,659 \\
\hline Total & $35,966,400$ & $8,222,094$ & $39,410,558$ & $9,018,616$ & 3,417 & 4,079 & 62,739 & 169,762 & $1,744 \|$ & $4,313^{\|}$ \\
\hline
\end{tabular}

${ }^{*} \mathrm{CSR}=$ cataract surgical rate; ${ }^{\dagger} \mathrm{BA}=$ Buenos Aires; ${ }^{\ddagger} \mathrm{C} A B A=$ greater metropolitan area of Buenos Aires; ${ }^{5}=$ data are incomplete, resulting in much lower estimates than expected $\|=$ mean.

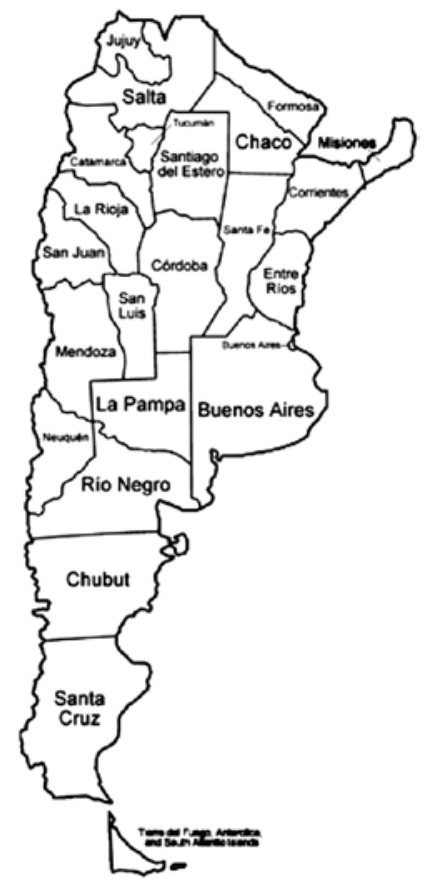

Figure 1. Map of Argentinean provinces.

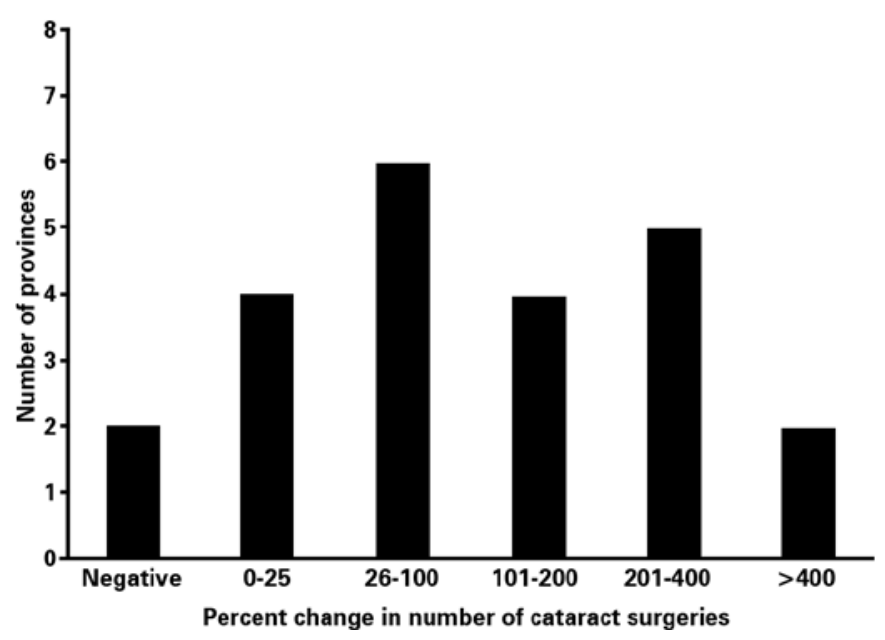

Figure 2. Percentage changes in the number of cataract surgeries categorized by value.

PAMI additionally offers coverage to other vulnerable social groups, including veterans, the disabled, and widows. While 186,652 IOLs were sold in 2008, 169,762 surgeries were reported. Therefore, 16,890 surgeries were not accounted for, although it is likely that some of the IOLs imported in 2008 may not have been used for cataract surgeries 


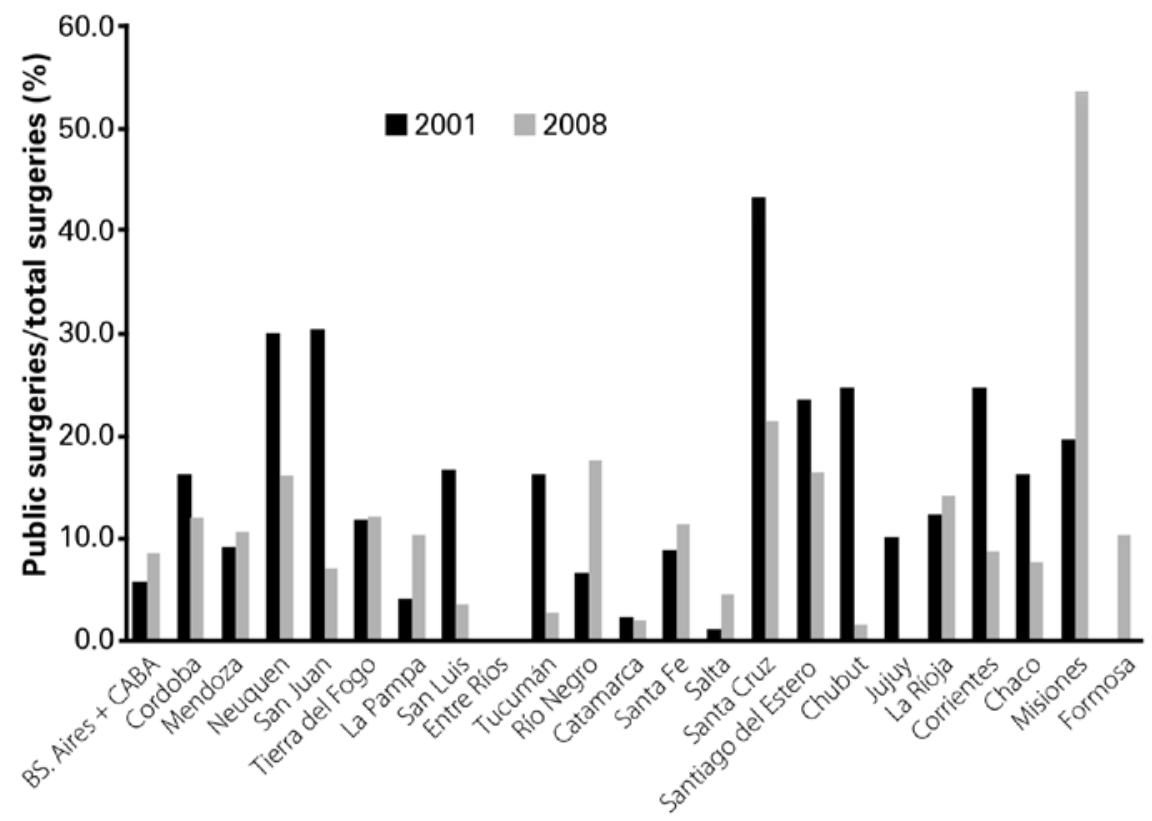

Figure 3. The number of public surgeries as a percentage of the total number of surgeries performed in 2001 and 2008 by province.

in that year. The numbers of IOLs sold in 2009 and 2010 were 173,395 and 233,498 , respectively.

\section{DISCUSSION}

This study represents the first national longitudinal survey of cataract surgery in a country (by province) of Latin America. Overall, the results demonstrated a large increase in the number of surgeries, particularly government-financed surgeries (from 5,762 to 14,006). The CSR increased from 2001 to 2008. However, this study highlights the difficulties in obtaining an accurate count of surgeries and, consequently, the CSR in some countries. This is important because the CSR is 1 of 3 components used to define the progress in national plans related to cataract blindness (the others are CSC and cataract surgical outcomes). Often, inaccurate CSRs are reported to be lower than the actual rate, so the situation appears worse than it actually is.

When CSR data for Argentina was published in 2010(12), IOL manufacturers were contacted to assure that the data presented were reasonably accurate. Indeed, data were in good agreement with $\mathrm{OL}$ sales data. However, when an update was recently requested, it was a surprise to find that figures from 2008 onward in Argentina had been enormously revised upward, largely because some sources had not been included. These revised figures suggested that approximately $52 \%$ IOLs were not accounted for in the actual number of surgeries reported in the initial 2008 survey. That is to say, more surgeries were performed than reported. The new IOL sales figures appear to be accurate because the 2008-2011 IOL sales data are all roughly in the same range, with some year-to-year fluctuations. Moreover, the data for PAMI is validated because PAMI manages cataract surgeries financed by the government on a contract basis to ophthalmologists, who cannot be paid without reporting surgeries directly to PAMI.

In 2008, it was estimated that Argentina had 128 ophthalmologists per million population (approximately 5,400 in total for a population of 39.4 million) and a CSR of approximately 2,350 per million population ${ }^{(12)}$. The more refined data presented in this study suggest that the number of ophthalmologists was considerably inflated; a more accurate total would be 4,100 (104 ophthalmologists per million population). Nevertheless, the trend toward an increased number of ophthalmologists continues, and Argentina has one of the highest number of ophthalmologists per capita in Latin America. Many ophthalmologists in Argentina do not perform cataract surgery. Many residencies are located in the private sector, where the majority of surgeries are performed by consultants nominated by patients and supported by insurance companies. Therefore, many residents work as clinical ophthalmologists rather than surgeons.

Using the revised IOL sales data, the true CSR for Argentina in 2008 was probably around 4,700, rather than the originally reported $2,350^{(12)}$. On the basis of the most recent IOL sales report, it can be assumed that today's CSR is approximately 5,000, which would actually place Argentina among the top CSR countries in Latin America.

This new method of CSR data collection was further validated by cross-checking CSR data with IOL inventories in Brazil, Peru, and Chile. According to industry reports, in Brazil, approximately 540,000 IOLs were imported by suppliers in 2011. In Peru, the reported number of IOLs sold in the country in 2010 was 45,500. In Chile, the estimated number of IOLs sold in the country was 65,000 in 2010. Therefore, working with an estimated population of 199.7 million in Brazil in $2011^{(13)}$, the calculated CSR based on IOL sales would be 2,704 or almost exactly the same as that $(2,700)$ reported recently to the WHO. Likewise, in Peru, the calculated rate based on a population of 29.4 million ${ }^{(13)}$ would be 1,548 or close to the 1,400 reported that year. Finally, in Chile, the calculated CSR would be 3,720 versus the reported 3,450 , indicating a discrepancy of $7.8 \%$. We therefore believe that the figures presented in this study were reasonably accurate. CSR accuracy depends on the number of surgeries reported and the population for a given year, which can vary considerably. For example, the Brazilian government's estimate was approximately 191 million in 2011, while the UN's estimate was near 200 million, which equates to a CSR difference of 123 (approximately a $4.5 \%$ variance).

Although it appears that the CSR in Argentina is much higher than believed, high CSR figures do not guarantee that individuals who need surgery actually undergo it because this metric is just a measure of cataract surgery consumption ${ }^{(12)}$. Moreover, surgical outcomes have to be considered. For example, if $25 \%$ surgeries are not meeting the WHO criteria, then the CSR should be discounted accordingly. To some extent, CSC data can provide snapshots in time 
of how many individuals are blind or visually impaired because of cataract. In Argentina, many regions have not yet been surveyed.

There was a large increase in the number of IOLs sold in Argentina between 2001 and 2008, from approximately 80,000 to 187,000, but this increase likely occurred after the results of the first RACCS study ${ }^{(10)}$ published in 2006 caused considerable alarm in the $\mathrm{MOH}$. The $\mathrm{MOH}$ and PAMI then established a Prevention of Blindness Committee with a focus on cataract surgery. Based on recent IOL sales and data from PAMI, PAMI now finances up to 80,000 cataract surgeries per year. The $\mathrm{MOH}$ also supports public surgeries in provinces that do not have any kind of coverage. Both these developments highlight the importance of $\mathrm{MOH}$ involvement in developing countries to increase the number of cataract surgeries.

There are several potential reasons why the initial survey method used in Argentina underestimated the number of surgeries. First, the presence of multiple ophthalmological societies in the country complicated the process of obtaining accurate data, particularly in the greater Buenos Aires area. For example, the number of ophthalmologists may be double-counted, and some ophthalmologists do not belong to either organization or are not board-certified. Second, and perhaps most importantly, private practitioners in ophthalmology may be afraid to fully report the number of cataract surgeries performed for various reasons such as taxation.

Therefore, a complete survey of Argentina by province demonstrated that the CSR increased impressively between 2001 and 2008. However, cross-checks with in-country IOL sales and PAMI data indicated that our previous reporting system was considerably underestimating the number of cataract surgeries. The method used in this study is now more aligned with the system successfully used in other Latin American countries and is more accurate because the number of surgeries reported can be validated with the number of IOLs sold. The findings of this study are being released simultaneously with the recent WHO mandate for governments to report CSRs. While this will facilitate future data collection in the public sector, it is necessary to note that in many countries such as Argentina, the majority of cataract surgeries are conducted in the private sector. As such, a reporting mechanism for private practitioners needs to be developed so that they are motivated to contribute their surgical data to the national statistics.

\section{ACKNOWLEDGEMENTS}

The authors would like to thank Nora Luedicke and Rosario Barrenechea of the Programa Nacional de Salud Ocular y Prevención de la Ceguera, Ministerio de Salud de la Nación, Buenos Aires, Argentina for help in collecting data on public surgeries. The authors would also like to thank all the ophthalmologists who helped in collecting data: Dr. Carlos Laje, Dr. Carlos Alberto Carranza, Dr. Emma Sonzini, Dr. Victor Forcada, Dr. Hernan Gras, Dr. Juliet Gras, Dr. Maria Alejandra Carrasco, Dr. Oscar Moretti, Dr. Christian Larrañaga, Dr. Osvaldo Roux, Dr. Cristina Aguado Casal, Dr. Manuel Flores, Dr. Raúl Ruffa, Dr. Nélida Rosso Nano, Dr. Ignacio Lichinsky, Dr. Jorge Lichinsky, Dr. Diana G. De Waisman, Dr. Myriam Berman, Dr. Isabel F. Roman, Dr. Elbio Hernández, Dr. Juan Carlos Casanovas, Dr. Joaquín Baffaluy, Dr. García Castellanos, Dr. Alberto Cruz, Dr. Richard Rubens Cárdenas, Dr. Jorge Echeverría, Dr. Pablo Emilio Passone, Dr. Patricia Larcher, Dr. Teresa Airasca, Dr. Fernando Suárez, Dr. Carlos Zarif, Dr. Ernesto Ferrer, Dr. Antonio Anzalaz, Dr. Héctor Vega Fernández, Dr. Bárbara Ventura, Dr. Gustavo Alarcón, Dr. Jorge Kleisinger, Dr. Horacio Martínez, and Dr. Italo Horacio Di Biase. Finally, the authors thank ORBIS for their financial support.

\section{REFERENCES}

1. Pesudovs K. Patient-centred measurement in ophthalmology-a paradigm shift. BMC Ophthalmol. 2006;6:25. Review.

2. Lansingh VC, Carter MJ, Martens M. Global cost-effectiveness of cataract surgery. Ophthalmology. 2007;114(9):1670-8.

3. Lewallen S, Williams TD, Dray A, Stock BC, Mathenge W, Oye J, et al. Estimating incidence of vision-reducing cataract in Africa: a new model with implications for program targets. Arch Ophthalmol. 2010;128(12):1584-9.

4. World Health Organization. Estimating cataract surgical services in national programs. Version 1.02, December 2001. [Programmed by Hans Limburg]. Geneva: World Health Organization. 2001 [cited 2013 May 2]. Available from: http://www.who.int/ncd/ vision2020_actionplan/documents/raccs/manuals/RACSSDOSManuaEngl.pdf

5. Kuper H, Polack S, Limburg H. Rapid assessment of avoidable blindness. Community Eye Health. 2006;19(60):68-9.

6. Lundström M, Stenevi U, Thorburn W. The Swedish National Cataract Register: A 9-year review. Acta Ophthalmol Scand. 2002;80(3):248-57.

7. Johnston RL, Sparrow JM, Canning CR, Tole D, Price NC. Pilot National Electronic Cataract Surgery Survey: I. Method, descriptive, and process features. Eye (Lond). 2005; 19(7):788-94.

8. Jaycock P, Johnston RL, Taylor H, Adams M, Tole DM, Galloway P, Canning C, Sparrow JM; UK EPR user group. The Cataract National Dataset electronic multi-centre audit of 55,567 operations: updating benchmark standards of care in the United Kingdom and internationally. Eye (Lond). 2009;23(1):38-49.

9. Murthy G, Gupta SK, John N, Vashist P. Current status of cataract blindness and Vision 2020: the right to sight initiative in India. Indian J Ophthalmol. 2008;56(6):489-94.

10. Nano ME, Nano HD, Mugica JM, Silva JC, Montaña G, Limburg H. Rapid assessment of visual impairment due to cataract and cataract surgical services in urban Argentina. Ophthalmic Epidemiol. 2006;13(3):191-7.

11. Kleisinger JE, Nano ME, Lansingh VC, et al. Estimating the number of cataract surgeries needed in the Chaco province of Argentina using various visual acuity (VA) thresholds and CSC. Ophthalmol Clin Exp. 2010;4(2):61-3.

12. Lansingh VC, Resnikoff S, Tingley-Kelley K, Nano ME, Martens M, Silva JC, et al. Cataract surgery rates in latin america: a four-year longitudinal study of 19 countries. Ophthalmic Epidemiol. 2010;17(2):75-81.

13. United Nations Department of Economic and Social Affairs. World population prospects: the 2010 revision. United Nations. 2010 [cited 2013 May 2]. Available from: http://esa.un.org/unpd/wpp/Excel-Data/population.htm. 